\title{
HEPARIN OR 0.9\% SODIUM CHLORIDE TO MAINTAIN CENTRAL VENOUS CATHETER PATENCY: A RANDOMISED TRIAL
}

\author{
B.V. Mahesh Babu1, A.S. Kameswara Rao², K. Rajesh³, V. Harinath Babu4
}

\section{HOW TO CITE THIS ARTICLE:}

B.V. Mahesh Babu, A.S. Kameswara Rao, K. Rajesh, V. Harinath Babu.“Heparin or 0.9\% Sodium Chloride to maintain Central Venous Catheter Patency: A RandomizedTrial". Journal of Evolution of Medical and Dental Sciences 2014; Vol. 3, Issue 01, January 06; Page: 46-50.

ABSTRACT: BACKGROUND: Maintaining the lumen patency of Central venous catheters (CVCs)using low dose Heparin is recommended in many guidelines of CVC maintenance. This study is to compare the efficacy of low-dose Heparin $3 \mathrm{ml}(10 \mathrm{U} / \mathrm{ml})$ and $0.9 \%$ Sodium chloride (10ml) flush solutions to maintain Central venous catheter (CVC) lumen patency. METHODS: We studied 100 adult patients between March 2012 and August 2012 who required short-term CVC insertion to compare two flush solutions, Heparin and $0.9 \%$ Sodium Chloride on catheter lumen patency. RESULTS: The crude catheter non patency was 4\% (two lumens)in Heparin group and 8\% (four lumens) in the Sodium Chloride group. There was no incidence of thrombocytopenia in both the study groups. CONCLUSION: This study has demonstrated no significant difference between Heparin and $0.9 \%$ Sodium Chloride flushes with regards to catheter patency in adult patients with short-term use of CVCs.

KEYWORDS: central venous, heparin, sodium chloride, vascular patency.

INTRODUCTION: Venous catheters generally develop a fibrin sheath at the tip, which evolve into a clot due to body's physiological response to the vein injury and the foreign catheter ${ }^{1}$ and subsequent catheter obstruction. Flushing a catheter lumen used for intermittent infusions is important. After an infusion or a flush, the reflux of blood into the lumen increases the risk of thrombus formation. Thrombus formation leads to loss of functionality of that lumen.Loss of lumen functionality due to thrombosis requires costly thrombolytic therapy or catheter removal2. Interventions to prevent catheter thrombosis occlusion \& maintain function of CVCs vary from unit to unit \& institute to institute. Heparin is the standard flush recommended in various CVC maintenance guidelines ${ }^{3-5}$.The switch to $0.9 \%$ Sodium Chloride may be due to the concerns of Heparin induced complications like Heparin induced thrombocytopenia (HIT) or bleeding (6). Therefore, we conducted a study to compare the efficacy of low-dose Heparin $3 \mathrm{ml}(10 \mathrm{U} / \mathrm{ml})$ and $0.9 \%$ Sodium chloride $(10 \mathrm{ml})$ flush solutions to maintain Central venous catheter(CVC) lumen patency in the Respiratory intensive care unit (RICU) of our tertiary referral hospital. The primary objective of this study is to compare the efficacy of low-dose Heparin $3 \mathrm{ml}(10 \mathrm{U} / \mathrm{ml})$ and $0.9 \%$ Sodium chloride $(10 \mathrm{ml})$ flush solutions to maintain Central venous catheter(CVC) lumen patency.

METHODS: After obtaining institutional ethical committee's approval, 100 patients aged between 18 to 58 years of both sexes who are admitted into the RICU(Respiratory Intensive Care Unit) with various disease processes were selected. They were assigned randomly into two groups consisting of 50 in each group, within $12 \mathrm{hrs}$. after CVC insertion. To be enrolled in the study, patients had to have a newly inserted triple lumen CVC $(<12 \mathrm{hrs})$, and all the lumens had to be patent. Heparin group (group H) who received Heparinflush solution and $0.9 \%$ sodium chloride group (group S) who 
received $0.9 \%$ sodium chloride flush solution. All the CVCs used for the study were triple lumen catheters (Certofix®Trio of B.Braun, made of Polyurethane).The size and length of the CVCs were same in all the patients. Distallumen was exclusively used for the study purpose only, while the other lumens were being used for the infusions. Exclusion criteria were Known Heparin allergy, diagnosis of Heparin induced thrombocytopenia (HIT), bleeding risk identified by attending physician, Age < 18 yrs. OR > 58 yrs., patients requiring prolonged ICU stay with ailments like terminal illness, severe septicemia, Multi Organ Dysfunction Syndrome (MODS) etc....

After obtaining consent within $12 \mathrm{hrs}$. after insertion of $\mathrm{CVC}$, the patient received either heparin (3 mL, $10 \mathrm{U} / \mathrm{mL}$ ) or $0.9 \% \mathrm{NaCl}(10 \mathrm{~mL}$ ) flushes every 8 hours. Daily at 8:00 AM, 4:00 PM and 12:00 AM the patency assessment was done. Therefore three patency assessments per day were possible for every case. All the RICU Residents were educated on study purpose, protocol, data collection, and the importance of adhering to regular flushingintervals. When a CVClumen nonpatency was encountered, it was reported and noted in the study. These assessments were performed until the patients were shifted out of the RICU or, the CVC was removed, whichever came first, with an average duration of 1 week.

Study outcome and definitions: The primary outcome of the study was lumen non-patency defined as inability to both withdraw blood and flush through a lumen. The conclusion of lumen nonpatency was arrived only after the following interventions:1. if the lumen could not be flushed, the patient was repositioned and flush reattempted.2.If still unable to flush, the syringe was changed and flush was reattempted. As a secondary outcome, heparin induced thrombocytopenia (HIT) was assessed with daily platelet count, starting on day 4 from the time of giving heparin flushes for all the patients in Group H.

Statistics analysis: Differences between the groups were assessed using student's test or chi-square test as appropriate. All statistical analyses were performed using SPSS version 17.0.

RESULTS: The demographic characteristics of the patients undergoing study are shown in the table. Baseline demographics and catheter and lumen characteristics were similar in both the groups. 


\section{CASE REPORT}

\begin{tabular}{|c|c|c|}
\hline AGE DISTRIBUTION & $\begin{array}{c}\text { GROUP H } \\
(n=50)\end{array}$ & GROUP S $(n=50)$ \\
\hline $18-28$ & 6 & 6 \\
\hline $29-38$ & 12 & 14 \\
\hline $39-48$ & 16 & 12 \\
\hline $49-58$ & 16 & 18 \\
\hline \multicolumn{3}{|l|}{ SEX DISTRIBUTION } \\
\hline MALE & 24 & 22 \\
\hline \multirow[t]{2}{*}{ FEMALE } & 26 & 28 \\
\hline & $\begin{array}{c}\text { GROUP H } \\
(n=50)\end{array}$ & GROUP S $(n=50)$ \\
\hline TYPE OF LUMEN & $\begin{array}{l}\text { TRIPLE } \\
\text { LUMEN }\end{array}$ & TRIPLE LUMEN \\
\hline \multicolumn{3}{|l|}{ LOCATION } \\
\hline IJV & 40 & 36 \\
\hline \multirow[t]{2}{*}{ SUBCLAVIAN } & 10 & 14 \\
\hline & $\begin{array}{c}\text { GROUP H } \\
(n=50)\end{array}$ & GROUP S $(n=50)$ \\
\hline $\begin{array}{c}\text { NON-PATENCY } \\
\text { (LOSS OF BLOOD } \\
\text { STREAM\& FLUSH } \\
\text { FAILURE) }\end{array}$ & $4 \%(n=2)$ & $8 \%(n=4)$ \\
\hline
\end{tabular}

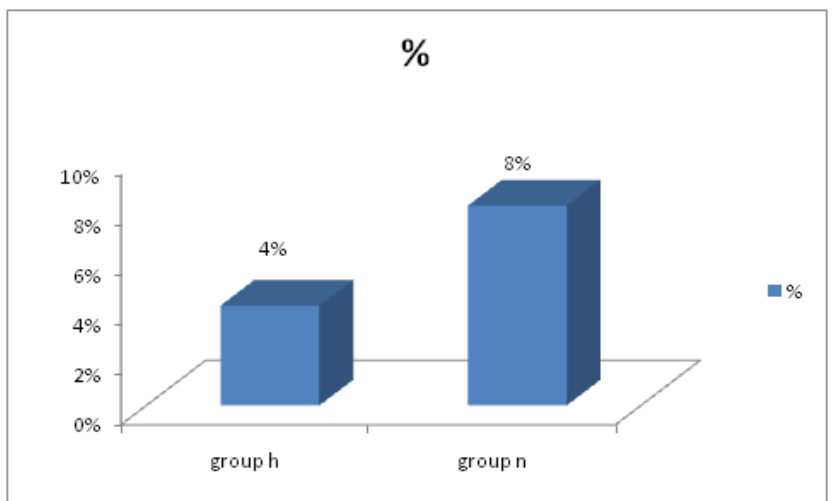

The crude catheter non patency was 4\% (two catheters) in heparin groupand 8\% (fourcatheters) in the sodium chloride group.

There was no incidence of thrombocytopenia in both the groups.

DISCUSSION: Central venous catheters (CVC's) are widely used in critical care to administera variety of blood products, intravenous (IV) fluids \& medications, to monitor hemodynamic indices, to obtain blood samples, \& for pacing or dialysis. Heparin is the standard flush recommended in various CVC maintenance guidelines. However $0.9 \% \mathrm{Nacl}$ is also used for the same purpose. This study demonstrated no difference between Heparin and $0.9 \% \mathrm{NaCl}$ flushes on maintaining patency of short-term CVC's in adults. Conflicting results were found in a randomized comparison of Heparin (5000IU / ml), Vitamin C (200 mg / ml), or) $0.9 \% \mathrm{NaCl}$ flush solutions used in distal lumens of triple 
lumen catheters ${ }^{7}$.Attempts to aspirate blood was performed every $48 \mathrm{hrs}$. The authors observed significant difference between the three groups, and concluded that Heparin is superior for maintaining catheter patency ${ }^{7}$.One major difference in this study was the flushing frequency of every 48 hours as compared to every 8 hours, and may partly account for the different findings. Systemic reviews of various CVCs have demonstrated insufficient evidence for superiority of flushing with Heparin compared to $0.9 \% \mathrm{NaCl}$. Likewise, a Cochrane review that analyzed the heparin bonded catheters with non-heparin bonded catheters found no significant difference in patency ${ }^{8}$. Matthew D. Mitchell1, Barbara Jo Anderson, Kendal Williams, Craig A. Umscheid ${ }^{2}$ concluded that the evidence base on heparin flushing and other interventions to prevent catheter occlusion is small, and published studies are of low quality. There is insufficient evidence on which to conclude that flushing catheters with heparin is more effective than flushing with saline solution.

In this study, 100 patients were randomly selected who have a newly inserted CVC $(<12 \mathrm{hrs})$ \& divided into two groups group H \& group S, with 50 patients in each group. One lumen in each CVC was exclusively used for study. Flushes with heparin or sodium chloride solutions were done every 8hrs.This study demonstrated no difference between heparin \& $0.9 \% \mathrm{NaCl}$ flushes on maintaining patency of short-term CVCs in adults. Simple interventions like position changing can sometimes correct loss of patency, thus eliminating the need for catheter removal. Systematic reviews of various CVCs have demonstrated insufficient evidence for superiority of flushing with heparin compared to $0.9 \% \mathrm{Nacl}^{2,9}$, and 10 .The primary outcome of the study was lumen non-patency defined as inability to both withdraw blood and flush through a lumen. The lumen was declared non-patent only after flushing with a position change and change in the syringe. Proper flushing/clamping sequence performed every 8 hours and catheter flushes after medication administration are worthwhile interventions to help maintain catheter patency. In our study, the primary outcome i, e; lumen non-patency was encountered in one catheter of heparin group (4\%) and in 2 catheters of sodium chloride group (8\%). None of them had complications during insertion or when the catheter was in situ. Thrombocytopenia was not found in both the groups.

CONCLUSION:In conclusion, this study has demonstrated no significant difference between heparin and $0.9 \% \mathrm{NaCl}$ flushes with regards to catheter patency in adult patients with short-term use of CVC's.Although measures of safety were similar in these two groups, saline flushes may be preferred to reduce exposure to heparin and its potential complications.Regular intervals of flushing, proper flushing/clamping sequence are likely the most important interventions to maintain catheter patency.

Previous presentation:The results of this study were presented as a free paper at the South zone conference of the Indian society of Anesthesiologists, Coimbatore 2012.

\section{REFERENCES:}

1. Yacopetti N:Central venous catheter- related thrombosis: A systemic review. J Infus Nurs 2008; 31:241-248.

2. Mitchell MD, Anderson BJ, Williams $\mathrm{K}$, et al: Heparin flushing and other interventions to maintain patency of central venous catheters: A systemic review. J AdvNurs2009; 65: 20072021.

3. Infusion nursing society: Standards of practice.J Intraven Nurs 2006; 29, IS: S55-S56. 
4. Baglin T, Barrowcliffe TW, Cohen A, et al; British Committee for standards in Hematology: Guidelines on the use and monitoring of heparin. Br J Haematol2006; 133;19-34.

5. Central venous access device guidelines Panel:Managing Central venous access devices in cancer patients. A clinical practice guideline.Cancer Care Ontario.2006.

6. Selleng K, Warkentin TE, Greinacher A: Heparin-induced thrombocytopenia in intensive care patients. Crit Care Med 2007;35: 1165-1176.

7. Rabe C. Gramman T, Sons X, et al: Keeping central venous lines open: A Prospective comparison of heparin, vitamin $\mathrm{C}$ and sodium chloride sealing solutions in medical patients, Intensive care Med 2002; 28:1172-1176.

8. Shah PS, Shah N: Heparin-bonded catheters for prolonging the patency of central venous catheters in children. Cochrane Database Syst rev 2007; (4): CD005983.

9. Bishop L, Dougherty L, Bodenham A, et al: Guidelines on the insertion and management of central venous access devices in adults. Int J Lab Hematol2007; 29:261-278.

10. Lee OK Johnston L : A systematic review for effective management of central venous catheters and catheter sites in acute care pediatric patients.Worldviews Evid Based Nurs 2005 ; 2:4-13.

\section{AUTHORS:}

1. B.V. Mahesh Babu

2. A.S. KameswaraRao

3. K. Rajesh

4. V. HarinathBabu

\section{PARTICULARS OF CONTRIBUTORS:}

1. Associate Professor, Department of Anesthesiology, RMC, Kakinada.

2. Dean \& Professor, Department of Anesthesiology, KIMS \& RF, Amalapuram.

3. $2^{\text {nd }}$ Year Post Graduate, Department of Anesthesiology, RMC, Kakinada.

4. Professor \& HOD, Department of

NAME ADDRESS EMAIL ID OF THE CORRESPONDING AUTHOR:

Dr.B.V. Mahesh Babu, Associate Professor, Department of Anesthesiology, RMC, Kakinada.

Email-bvmaheshbabu@gmail.com

Date of Submission: 27/11/2013. Date of Peer Review: 28/11/2013. Date of Acceptance: 17/12/2013. Date of Publishing: 01/01/2014 